\title{
Custo Total de Propriedade de Veículos de Transporte de Funcionários: Estudo de Caso
}

\begin{abstract}
Nelize Aparecida de Souza Pós-Graduação em Gestão de Negócios pela Universidade do Sul de Santa Catarina Auxiliar de Escritório na SJK Facção Têxtil Ltda Estrada Geral do Bairro Lage, Treze de Maio/SC. CEP 88.710-000 E-mail: nelize_aparecidaa@hotmail.com

Rodney Wernke Doutorado em Engenharia de Produção pela Universidade Federal de Santa Catarina UFSC Professor da Universidade do Sul de Santa Catarina - UNISUL Avenida José A. Moreira, 787. Dehon. Tubarão/SC. CEP 88.704-900 E-mail: rodneywernke1@hotmail.com

Antonio Zanin Doutorado em Engenharia de Produção pela Universidade Federal do Rio Grande do Sul - UFRGS Professor da Universidade Comunitária da Região de Chapecó - UNOCHAPECÓ Servidão Anjo da Guarda, 295-D. Efapi. Chapecó/SC. CEP: 89809-900 E-mail:zanin@unochapeco.edu.br
\end{abstract}

\section{RESUMO}

Este estudo objetivou identificar os custos totais da propriedade de dois veículos utilizados para transportar funcionários de determinada fábrica de confecções. Para essa finalidade, foi utilizada metodologia descritiva, com abordagem qualitativa e no formato de estudo de caso. Entre os resultados, cabe destacar que os fatores considerados (exclusive o custo de aquisição dos veículos) representaram a parte mais substancial do CTP/TCO: $88,72 \%$ no veículo Mercedes-Benz e 79,09\% no caso do veículo Volkswagen. Além disso, quanto aos montantes finais calculados, chegou-se a valores distintos para os dois ônibus, sendo que o veículo Mercedes-Benz teve desempenho superior em relação ao Volkswagen, especialmente se considerado o parâmetro de custo por quilômetro rodado: $R \$ 6,933$ contra $R \$ 7,326$. A diferença verificada de $R \$ 0,393$ a cada 1.000 metros percorridos equivale a aproximadamente $5,67 \%$ a favor do primeiro ônibus. Como contribuições práticas do estudo, além de proporcionar uma avaliação mais acurada acerca do desempenho dos dois veículos na realidade operacional cotidiana, concluiu-se que um dos dois ônibus é economicamente mais viável que o outro, o que pode subsidiar decisões sobre terceirizar ou manter frota própria. No âmbito teórico, contribuiu-se com a evidenciação de uma aplicação do conceito de CTP/TCO num contexto ainda não identificado em pesquisas correlatas. 
Palavras-chave: Custo total de propriedade. Veículos de transporte de funcionários. Estudo de caso.

\title{
Total Cost of Ownership of Employee Transport Vehicles: Case Study
}

\begin{abstract}
The objective was to identify the total costs of ownership of two vehicles used to transport employees of a particular garment factory. For this purpose a descriptive methodology was used, with a qualitative approach and in the case study format. Among the results, it should be noted that the factors considered (excluding vehicle acquisition cost) represented the most substantial part of the CTP / TCO: $88.72 \%$ in the Mercedes-Benz vehicle and $79.09 \%$ in the Volkswagen case. In addition, for the final amounts calculated, there were different values for the two buses, and the MercedesBenz vehicle performed better in relation to Volkswagen, specially considering the parameter of cost per kilometer rolled: $R \$ 6,933$ against $R \$ 7,326$. The difference of $R \$$ 0.393 per 1,000 meters is equivalent to approximately $5.67 \%$ in favor of the first bus. As practical contributions of the study, in addition to providing a more accurate assessment of the performance of the two vehicles in everyday operational reality, it was concluded that one of the two buses is economically more viable than the other, which subsidizes decisions about outsourcing or maintaining own fleet. In the theoretical framework, the application of the CTP / TCO concept was highlighted in a context not yet identified in related research.
\end{abstract}

Keywords: Total cost of ownership. Employee transportation vehicles. Case study.

\section{INTRODUÇÃO}

Para que as organizações possam sustentar-se no mercado dinâmico e competitivo da atualidade, a gestão das compras é fator relevante, especialmente para manter a competitividade perante os concorrentes. Nesse sentido, a partir da área de compras, é possível reduzir custos que diversas vezes passam despercebidos pela administração da empresa, especialmente no caso da aquisição dos materiais a serem consumidos na produção, que costumam representar importante parcela dos gastos fabris (Wernke, 2014).

Contudo, a maioria das decisões de compras baseia-se apenas na verificação dos preços mais baixos, visto que os compradores precisam decidir qual a melhor forma 
de adquirir determinado produto/serviço, visando à redução de custos e ao aumento da produtividade. Com isso, acabam por desconsiderar o fato de que outras variáveis (além do preço do fornecedor) podem representar custos não expressos na nota fiscal de aquisição. Portanto, caberia considerar os demais aspectos que são abrangidos pelo conceito denominado Custo Total de Propriedade - CTP (ou Total Cost of Ownership TCO), conforme proposto por Ellram e Siferd (1993) e Ellram (1995).

A partir dessa concepção, é pertinente dessumir que o CTP/TCO seja adaptável em vários contextos, como comprovam pesquisas que o aplicaram no âmbito da aquisição de veículos de carga (Camargo, Zanin, Wernke, \& Scheren, 2016; Wernke, Lembeck, \& Mendes, 2012), de automóveis para uso particular (Wernke, 2015) e de equipamentos industriais (Coser \& Souza, 2017; Mochnacz, Deimling, Barichello, Kliemann Neto, \& Casarotto Filho, 2017), entre outras possibilidades.

Destarte, provavelmente este conceito pode ser utilizado também na avaliação dos ônibus que transportam funcionários de determinada fábrica com o objetivo de se conhecer quais seriam os tipos de veículos economicamente mais viáveis para tal finalidade. A partir desta cogitação é que emergiu a questão de pesquisa que se pretendeu abordar neste estudo: como avaliar o custo total de propriedade dos ônibus de transporte de empregados de uma indústria de confecções? Para essa finalidade, foi estabelecido o objetivo de identificar os custos associados à propriedade de dois veículos utilizados para transportar funcionários de determinada fábrica de confecções.

Estudos como estes se justificam por, pelo menos, dois aspectos. O primeiro é que a manutenção de uma frota própria de ônibus, mesmo que em número reduzido de veículos, implica custos que sequer podem estar sendo computados nas avaliações realizadas pelos gestores das pequenas empresas fabris. Com isso, a análise da viabilidade econômica de mantê-los ou terceirizá-los é prejudicada porque nem todos os fatores envolvidos estão devidamente considerados na decisão do administrador a respeito.

O segundo ponto refere-se à baixa sintonia entre estudos acadêmicos e as necessidades de informações que os gestores possuem, o que tem sido objeto de 
pesquisas há muito tempo na literatura, como atestam várias publicações (Scapens, 2006; Ahrens \& Chapman, 2007; Malmi \& Granlund, 2009; Seal, 2010; Coleman, 2014; Bartunek \& Rynes, 2014; Antunes, Mendonça Neto, \& Vieira, 2016). Acerca disso, defende-se que há uma necessidade de pesquisas acadêmicas que auxiliem as empresas a aplicar, na prática cotidiana destas, os conceitos da contabilidade gerencial existentes na literatura (Baldvinsdottir, Mitchell, \& Norreklit, 2010; Lukka, 2010). Assim, estudos com o viés prático priorizado neste estudo de caso podem contribuir para reduzir a lacuna da pesquisa mencionada.

Quanto à sua estrutura, além desta parte introdutória, o artigo contém uma revisão da literatura sobre CTP/TCO, outra seção que comenta os aspectos relacionados à metodologia de pesquisa utilizada e uma parte que apresenta os resultados do estudo e comenta sobre eles.

\section{REVISÃO DE LITERATURA}

A contabilidade de custos tem duas funções relevantes, onde a primeira é auxiliar no controle e a segunda consiste em fornecer subsídios que facilitem as tomadas de decisões pelos administradores. No que tange ao controle, este é realizado comparando-se padrões e confrontando o orçado (previsto) com o que foi efetivamente realizado. Em relação à tomada de decisão, cabe-lhe cumprir o papel de fornecer informações sobre valores e o impacto destes sobre os custos dos produtos, dos serviços e dos bens adquiridos no curto e no longo prazo (Martins, 2010).

Este último aspecto relacionado com os efeitos dos valores de custos ao longo do tempo também pode ser considerado por dois ângulos. No caso das aquisições cotidianas (curto prazo) é salutar compreender que a soma despendida com a aquisição de insumos para a produção, seja ela de produtos ou de serviços, representa valores que podem chegar entre $50 \%$ e $80 \%$ do total das receitas brutas (Martins \& Alt, 2006). Desse modo, é possível concluir que quaisquer benefícios obtidos nas 
aquisições de insumos podem facilmente implicar aumento do lucro do empreendimento.

Porém, geralmente considera-se que o custo de compra de um produto é dado pelo preço pago pelo comprador, mas, dessa forma, ignoram-se outros custos que incidem sobre a aquisição, posse, aplicação e descarte (Grant, 2013). Com isso, é interessante que os compradores avaliem o custo total do produto adquirido no transcorrer de toda a sua vida útil e não apenas o preço de compra (que deveria ser apenas um dos fatores analisados), de modo que sejam considerados na decisão fatores pré-transacionais, transacionais e pós-transacionais (Ellram \& Siferd, 1993).

Esta última concepção está associada ao conceito do Custo Total de Propriedade (CTP/TCO), que se qualifica como um método de avaliação que analisa um conjunto de fatores que vão além daqueles componentes do preço de compra de um produto ou serviço (Ellram, 1995). Desse modo, o cômputo do custo total de propriedade proporciona oportunidades de redução de custos para a empresa compradora e, também, para toda a cadeia de valores na qual a companhia está inserida. Isso ocorre porque, quando a decisão de comprar um bem está fundamentada exclusivamente no preço da aquisição, é provável que seja desdenhado um rol de gastos associados ao mesmo (Parisi \& Megliorini, 2011).

Nesse rumo, o CTP/TCO pode ser considerado uma ferramenta direcionada para a compreensão dos custos de aquisição de um bem ou serviço de um fornecedor específico e que este requer que o comprador determine quais são os custos mais relevantes para a aquisição, manuseio e subsequente disposição desse bem ou serviço (Gasparetto, Freires, Bornia, \& Rodrigues, 1999).

Por diversas vezes, nas mais diferentes situações, gastos importantes que são decorrentes de outras atividades relacionadas à aquisição (como pesquisa e qualificação do fornecedor, recebimento, inspeção, rejeição, reposição e correção de falhas) são ignorados. Mas, o uso do CTP/TCO permite a compreensão dos custos relevantes subjacentes à aquisição e ao uso de um bem ou serviço, o que auxilia nas 
decisões relacionadas às transações de compra e pode ser usado para avaliar o desempenho dos fornecedores (Faria, 2003).

O Custo Total de Propriedade é uma aproximação estruturada para que se determine o montante associado à aquisição e, posteriormente, à utilização de um dado item ou serviço de determinado fornecedor. Trata-se, então, de uma ferramenta voltada à compreensão dos custos de aquisição de um bem ou serviço de um fornecedor específico (Carr \& Ittner, 1992).

Acerca disso, a título de exemplificação, menciona-se o caso do iceberg para representar o custo total de propriedade, onde o topo do iceberg (parte não submersa) representa o preço pago ao fornecedor, enquanto que a parte submersa do iceberg equivale a todos os demais custos para adquirir, utilizar e descartar o produto. Destacase, ainda, que o custo total de propriedade pode ser bastante superior ao preço de compra em muitos casos, o que motiva apurar os valores a respeito (Bierma \& Waterstraat, 2004).

Na mesma linha de raciocínio, vale ter sempre em mente o conceito de custo de troca: mesmo que uma nova tecnologia seja melhor, há o custo da migração da atual em uso para aquela a ser adquirida (Porter, 2011). Referido autor usa como exemplo o procedimento comum de ter que passar toda a informação do celular antigo para o novo. Portanto, para o adquirente, é necessário ter certeza de que minimizou o custo de troca.

Por outro prisma, entre os principais motivos para adotar o CTP/TCO, podem ser elencados os aspectos no sentido de que: são úteis como suporte decisório para a seleção de fornecedores; favorecem o estabelecimento de medidas para a avaliação de desempenho dos fornecedores; e facilitam o direcionamento para mudança de processos organizacionais (Gasparetto et al., 1999).

A próxima seção discorre sobre a determinação do custo total de propriedade. 


\subsection{Aplicação do CTP/TCO}

No que concerne ao cálculo do custo total de propriedade, a abordagem deste pode variar para determinadas categorias de compras e, por esse motivo, é interessante segregar os tipos de compras em quatro categorias: componentes e materiais; bens de capital; itens de manutenção, reparo e operação e serviços (Ellram \& Sifferd, 1993). Entretanto, os referidos autores dividiram a determinação do CTP/TCO em três categorias de componentes que facilitam a respectiva identificação e posterior mensuração:

a) Pré-transacionais: relacionam-se com a identificação das necessidades atreladas à aquisição, como investigar as fontes de fornecimento, qualificar as fontes, aumentar o rol de fornecedores e a adequação/treinamento de fornecedores para a empresa e da empresa para fornecedores;

b) Transacionais: neste caso, devem ser considerados os aspectos relacionados com os gastos vinculados ao preço de compra, à colocação em funcionamento, à entrega (fretes e forma de transporte), às taxas ou encargos fiscais ou aduaneiros, à forma de faturamento (taxa de juros e prazos), à inspeção da qualidade, à possibilidade de devolução e aos serviços de assistência técnica ou pós-venda;

c) Pós-transacionais: referem-se aos aspectos de obsolescência, produtos defeituosos, falhas de campo, consertos e disponibilidade de peças de reposição, custos de manutenção do bem e custo das peças para manutenção.

Como exemplo da mensuração prática, Degraeve e Roodhoof (1999) relatam o problema da empresa Cockerill Sambre, que almejava encontrar o melhor fornecedor para adquirir eletrodos de aquecimento (cilindros de carbono com um comprimento de 2 metros e um diâmetro de cerca de 80 milímetros). Por meio de informações coletadas na empresa, tomou-se conhecimento de que os diversos custos, para além do preço de compra da peça, equivaliam a mais de $80 \%$ do CTP/TCO. Nesse rumo, tal companhia priorizava a qualidade como parâmetro na escolha do fornecedor de eletrodos de 
aquecimento (cujas características principais são a durabilidade e o baixo índice de defeitos), uma vez que a cada troca de eletrodos há a necessidade de um setup, cujos custos equivalem a $75 \%$ do CTP/TCO.

Degraeve e Roodhoof (1999) mencionam ainda que o critério seguinte ao da qualidade era o preço de aquisição da peça, cuja diferença entre os fornecedores era significativa, e alguns aceitavam a devolução do material usado porque este poderia ser reciclado. Além disso, o tamanho dos lotes era um critério considerado (cuja definição era feita pelos próprios fornecedores) porque, se a quantidade mínima do lote fosse muito elevada, a aquisição tornar-se-ia pouco flexível (mesmo que os custos com fretes ficassem bem menores).

Avaliou-se, também, o tempo do estoque de segurança que a empresa compradora deveria ter (de acordo com a confiabilidade do prazo de entrega dos fornecedores), bem como o prazo de pagamento das compras (cuja extensão variava de acordo com cada fornecedor e podia ser de até três meses). Por fim, foi computado o tempo que o gestor de compras despendia para analisar e gerir as negociações com os fornecedores. Então, pela aplicação do CTP/TCO, constatou-se que os custos de aquisição dos eletrodos poderiam ser reduzidos em $8 \%$ pelo fato de englobarem todos os fatores de custos, ao invés de se analisar apenas o preço de compra unitário do insumo (Degraeve \& Roodhoof, 1999).

Adicionalmente, é interessante destacar que tal ferramenta pode ser utilizada nas mais diversas formas de compras e tipos de segmentos comerciais, como atestam diversas publicações a respeito (Muller \& Panitz, 2001; Gasparetto \& Silva, 2004; Ignacio, Fernandes, Sampaio, \& Araújo, 2006; Schmidt, Santos, Pinheiro, \& Nunes, 2013; Deimling, Giongo, \& Zanrosso, 2012; Eisenbach Neto, Magalhães, \& Santos, 2013; Barichello, Carvalho, Pereira, Luza, \& Deimling, 2014; Coser \& Souza, 2017; Mochnacz et al., 2017).

Quanto ao contexto da compra e manutenção de um veículo (foco deste estudo), Cherobim e Espejo (2011) enumeram uma lista de possíveis dispêndios com os quais os proprietários de "veículos de passeio" se deparam e classificam-nos em gastos de 
natureza fixa e variável. Porém, tais autores somente elencaram os prováveis fatores a considerar, sem demonstrar efetivamente como apurá-los e o impacto destes para o comprador durante toda a vida útil do bem.

Por outro lado, Wernke et al. (2012) abordaram os fatores que deveriam ser computados para calcular o CTP/TCO, relacionados com a aquisição e manutenção de frota de veículos de carga, e demonstraram como calcular cada um dos itens a serem inseridos na evidenciação do valor total a respeito.

De forma assemelhada, Camargo et al. (2016) propuseram um modelo de mensuração do Custo Total de Propriedade (CTP/TCO) que permite comparar duas marcas diferentes de veículos "raçãozeiros" (caminhões que são utilizados no transporte de insumos da cadeia produtiva de suínos). A metodologia adotada permitiuIhes concluir que os fatores pré-transacionais da decisão de compra do caminhão representaram 20,21\% para o modelo da Volkswagen e 18,55\% para o modelo Ford, em relação ao CTP/TCO que a empresa terá no transcorrer da vida útil prevista para os dois veículos. Com isso, os elementos transacionais e pós-transacionais, conforme classificação de Ellram e Siferd (1993), representaram entre $79,79 \%$ e $81,45 \%$ do custo total previsto.

\section{METODOLOGIA}

Para que o pesquisador tenha à sua disposição um norte em relação às fontes e ferramentas utilizadas no estudo, a metodologia é imprescindível na pesquisa científica. A respeito disso, aduz-se que a pesquisa tem um caráter pragmático, pois é um processo formal e sistemático de desenvolvimento do método científico, e encontrar respostas empregando procedimentos científicos é o objetivo fundamental de uma pesquisa (Gil, 1999).

Quanto às características metodológicas, este estudo pode ser classificado como descritivo, qualitativo e com adoção do procedimento do estudo de caso. Ou seja, no que tange aos objetivos, classifica-se como descritivo porque esta categoria refere-se 
àqueles estudos que observam os fatos, registram-nos, analisam-nos, classificam-nos e interpretam-nos sem que o pesquisador interfira (Andrade, 2002).

No que concerne à forma de abordagem do problema, esta pesquisa pode ser adjetivada como qualitativa, visto que esta modalidade denomina os estudos que podem vir a descrever a complexidade de determinado problema, analisar a interação de determinadas variáveis, compreender e classificar processos dinâmicos vivenciados por determinados grupos sociais (Richardson, 1999).

Em relação aos procedimentos adotados, classifica-se como estudo de caso. A respeito dessa categoria, Yin (2001) qualifica-a como sendo uma estratégia de pesquisa que compreende um método que abrange abordagens específicas de coletas e análise de dados.

Quanto à escolha da empresa, a opção pela mesma ocorreu em virtude da facilidade de acesso aos dados, pois o proprietário se dispôs a colaborar com os pesquisadores prestando as informações necessárias e autorizando a coleta dos dados requeridos nas diversas fontes (contabilidade, controles internos, documentos dos veículos etc.) e a realização de entrevistas com funcionários.

Para obter os dados necessários ao estudo e com o intuito de inteirar-se da atual situação dos controles internos utilizados pela empresa, inicialmente foram realizadas entrevistas informais (não estruturadas) com o proprietário da fábrica e com o contador (assessoria contábil terceirizada). Quanto às perguntas feitas a estes, relacionavam-se basicamente com os controles internos utilizados e os possíveis custos mensais e anuais aos quais os veículos estariam sujeitos. Convém salientar ainda que tais entrevistas tiveram duração aproximada (total) de cinco horas e não foram gravadas.

Em seguida, passou-se à etapa de coligir os dados necessários para mensurar o CTP/TCO, que foram obtidos em fontes como: manual dos veículos; sites de empresas especializadas e órgãos de trânsito; contabilidade (terceirizada) da empresa; controles internos da administração da companhia, prestadores de serviços etc. Contudo, em alguns casos, foi necessário recorrer às estimativas do proprietário do empreendimento 
acerca de fatores mais subjetivos, como expectativa de vida útil dos veículos, estimativa de quilometragem média mensal/anual etc.

Quanto aos aspectos formais, para avaliar o rigor metodológico deste estudo de caso, foram utilizados os critérios recomendados por Marques, Camacho e Alcantara (2015) no que concerne aos seguintes aspectos:

1) Objeto de estudo: procurou-se entender o fenômeno visado no seu contexto real; foram explicadas as razões de adotar esta estratégia de pesquisa; verifica-se a existência de ligação entre o fenômeno em questão e o contexto pesquisado; a questão de estudo está claramente formulada e o tipo de estudo é descritivo.

2) Coleta de dados: há diversas formas de evidenciação (entrevistas com gestores e funcionários, documentação dos veículos, controles internos e registros contábeis) que permitem triangular os dados considerados na pesquisa; é possível comprovar a fidedignidade dos dados utilizados pelos controles internos e contábeis; medidas operacionais (como custo total de propriedade dos veículos, custo por quilômetro rodado, entre outras) foram elaboradas para validar o constructo estudado; são comentadas as formas como os dados foram obtidos e há a possibilidade de replicar a coleta de dados em outro contexto assemelhado.

3) Análise dos dados: os resultados decorrentes do estudo advêm dos dados coletados e foi empregada teoria anterior para embasar as análises efetuadas.

4) Resultados oriundos: foram comentadas as contribuições em relação a estudos precedentes, bem como foram citados alguns pontos que ainda precisam de continuação nesse tipo de investigação.

A próxima seção descreve, em detalhes, as fases de coleta de dados e de apuração dos resultados no contexto pesquisado. 


\section{APRESENTAÇÃO DOS DADOS E DISCUSSÃO DOS RESULTADOS}

Para que fosse mensurado o Custo Total de Propriedade (CTP/TCO) na empresa, objeto de estudo, foi necessário coletar dados junto aos gestores desta a partir da documentação dos dois ônibus (Mercedes-Benz e Volkswagen) utilizados para transporte dos funcionários, levando em conta o trajeto feito diariamente durante 0 período anual de atividades da empresa.

Nesse sentido, na Tabela 1 constam os dados iniciais levantados acerca dos dois veículos.

Tabela 1

\section{Dados dos veículos}

\begin{tabular}{|c|c|c|}
\hline Itens & VEÍCULO (A) & VEÍCULO (B) \\
\hline Descrição & Ônibus & Ônibus \\
\hline Marca & M. Benz & Volkswagen \\
\hline Ano/Modelo & $1993 / 1994$ & $2001 / 2001$ \\
\hline Potência & 48P $184 \mathrm{CV}$ & 29P $145 \mathrm{CV}$ \\
\hline Combustível (Diesel) $\mathrm{R} \$ /$ litro & 3,29 & 3,29 \\
\hline Quilometragem média/mês & $600 \mathrm{Km}$ & $720 \mathrm{Km}$ \\
\hline Vida útil estimada (anos) & 4 anos & 5 anos \\
\hline Código Tabela FIPE & $509003-2$ & $515105-8$ \\
\hline (a) Valor do Bem à Vista $R \$$ & $20.000,00$ & $60.000,00$ \\
\hline (b) CRLV R\$ & 81,39 & 81,39 \\
\hline (c) DPVAT R $\$$ & 103,78 & 103,78 \\
\hline (d) IPVA R\$ & 461,54 & 461,54 \\
\hline $1=a+b+c+d)$ Custo de Aquisição (Veículo + documentos) $R \$$ & $20.646,71$ & $60.646,71$ \\
\hline
\end{tabular}

Nota. Fonte: elaborada pelos autores.

Como visto, na Tabela 1 constam as principais características dos veículos utilizados no transporte dos funcionários: um ônibus Mercedes-Benz, ano/modelo 1993/1994, e um ônibus Volkswagen, ano/modelo 2001/2001. Em relação à quilometragem mensal, estimou-se que o ônibus Mercedes-Benz percorreria cerca de $600 \mathrm{~km} / \mathrm{mês}$, enquanto que o Volkswagen faria trajeto de aproximadamente 720 
$\mathrm{km} / \mathrm{mês}$ (ambos considerando o percurso diário completo de ida ao trabalho e retorno dos funcionários para suas residências).

Quanto ao preço do combustível, este foi registrado conforme o preço vigente à época da pesquisa e que era cobrado pelo fornecedor habitual da empresa para este insumo.

No que tange à vida útil estimada, esta foi determinada a partir da expectativa do proprietário da empresa de manter os veículos por mais quatro anos (48 meses) no caso do Mercedes-Benz e cinco anos (60 meses) para o outro veículo. Quanto ao valor atual desses ônibus, o montante respectivo foi apurado pela avaliação constante na "Tabela FIPE" para veículos com as características dos abrangidos neste estudo (R\$ 20.000 para o Mercedes-Benz e $\mathrm{R} \$ 60.000$ para o Volkswagen).

Além disso, foram levantados dados a respeito dos valores relacionados com a documentação destes, onde foram apurados os valores referentes ao CRLV (Certificado de Registro e Licenciamento de Veículos), DPVAT (Seguro de Danos Pessoais Causados por Veículos Automotores de Vias Terrestres) e IPVA (Imposto sobre a Propriedade de Veículos Automotores), conforme consta dos controles internos da empresa.

Somados os valores respectivos desses quatro fatores, chegou-se ao montante de $R \$ 20.646,71$ para o ônibus Mercedes-Benz (em que o valor de $R \$ 20.000$ refere-se à aquisição à vista do veículo e $R$ \$ 646,71 estão associados à documentação do veículo (CRLV, DPVAT e IPVA, como citado no parágrafo anterior e detalhado na Tabela 3, posteriormente). Por sua vez, para o ônibus Volkswagen, foi calculado o total de $R \$ 60.646,71$, em que $R \$ 60.000$ referem-se à compra deste e $R \$ 646,71$ referemse aos documentos legais exigidos para este tipo de bem (CRLV, DPVAT e IPVA).

$\mathrm{Na}$ etapa seguinte, foi mensurado o custo do capital aplicado, conforme descrito na Tabela 2, a título de exemplo para o ônibus Mercedes-Benz. 
Tabela 2

Custo do capital aplicado - Ônibus Mercedes-Benz

\begin{tabular}{lcccc}
\hline \multicolumn{1}{c}{ Itens } & Ano 1 & Ano 2 & Ano 3 & Ano 4 \\
\hline a) Custo de aquisição R $\$$ & $20.646,71$ & $20.646,71$ & $20.646,71$ & $20.646,71$ \\
b) Taxa de juros anual (Selic \% a.a.) & $6,75 \%$ & $6,75 \%$ & $6,75 \%$ & $6,75 \%$ \\
$2=a^{*}$ b) Custo do capital aplicado R $\$$ & $1.393,65$ & $1.393,65$ & $1.393,65$ & $1.393,65$ \\
\hline
\end{tabular}

Nota. Fonte: elaborada pelos autores.

O valor aplicado na compra do veículo poderia ser utilizado em outra modalidade de investimento, como no mercado financeiro, por exemplo. Contudo, por decidir investir na aquisição destes veículos, o capital empregado também deve ser remunerado ao menos pelo valor equivalente, a título de "custo da oportunidade" desprezada. Apesar de existirem metodologias de cálculo mais aprimoradas (como Custo Médio Ponderado de Capital - CMPC/WACC), optou-se por empregar uma taxa de juros de fácil obtenção para possibilitar a atualização posterior da planilha ora descrita. Assim, foi considerada a Taxa Selic anual de 6,75\%, conforme vigente à época do estudo, e a mesma foi multiplicada pelo custo de aquisição apurado na tabela anterior para cada veículo. No caso retratado na Tabela 2, o Mercedes-Benz tinha custo anual de oportunidade na ordem de $\mathrm{R} \$ 1.393,65$, e este valor foi utilizado em etapa posterior do cálculo do CTP/TCO.

No prosseguimento do estudo, foram estimados os gastos relativos à documentação anual dos veículos, como descrito de forma resumida na Tabela 3.

Tabela 3

\section{Custo da documentação anual - Mercedes-Benz}

\begin{tabular}{lcccc}
\hline \multicolumn{1}{c}{ Itens } & Ano 1 & Ano 2 & Ano 3 & Ano 4 \\
\hline a) Emissão CRLV R $\$$ & 81,39 & 81,39 & 81,39 & 81,39 \\
b) DPVAT R $\$$ & 103,78 & 103,78 & 103,78 & 103,78 \\
c) IPVA & 461,54 & 461,54 & 461,54 & 461,54 \\
3=a+b+c) Custo total da documentação R $\$$ & 646,71 & 646,71 & 646,71 & 646,71 \\
\hline
\end{tabular}

Nota. Fonte: elaborada pelos autores. 
No caso em lume, os valores para os próximos anos foram "previstos" porque os valores efetivos são divulgados anualmente pelo Departamento Estadual de Trânsito (DETRAN). Assim, assumiu-se que o valor do "Ano 0" seria o mesmo para os demais, em virtude da indisponibilidade dos valores futuros. Cabe ressaltar, também, que nesse total não está incluso o valor referente ao serviço do despachante, pois este não é utilizado porque as taxas são pagas diretamente pela empresa no site do órgão de trânsito.

Na sequência do estudo, foi abordado o aspecto dos gastos com a manutenção periódica conforme retratado na Tabela 4.

Tabela 4

Custo com manutenção periódica - Mercedes-Benz

\begin{tabular}{lcccc}
\hline \multicolumn{1}{c}{ Itens } & Ano 1 & Ano 2 & Ano 3 & Ano 4 \\
\hline a) Lubrificantes (a cada 12 meses) $\mathrm{R} \$$ & 208 & 208 & 208 & 208 \\
b) Filtros (a cada 12 meses) $\mathrm{R} \$$ & 35 & 35 & 35 & 35 \\
c) Pneus (a cada a cada 24 meses) $\mathrm{R} \$$ & - & $5.970,00$ & - & $5.970,00$ \\
d) Engraxar (R $\$ 50 / \mathrm{mê}^{*} 12$ meses) $\mathrm{R} \$$ & 600 & 600 & 600 & 600 \\
e) Lavagem (R $\$ 100 * 12 /$ ano) $\mathrm{R} \$$ & $1.200,00$ & $1.200,00$ & $1.200,00$ & $1.200,00$ \\
4=a+...+e) Custo total com manutenção $\mathrm{R} \$$ & $2.043,00$ & $8.013,00$ & $2.043,00$ & $8.013,00$ \\
\hline
\end{tabular}

Nota. Fonte: elaborada pelos autores.

No caso da manutenção do ônibus Mercedes-Benz, esta deve ser realizada a cada $10.000 \mathrm{~km}$ ou de acordo com a necessidade de cada veículo em termos de reparos ocasionais (que costumam ser executados no próprio posto de combustíveis onde são abastecidos os veículos e em oficinas/borracharias da cidade onde está situada a empresa em estudo). Destarte, quanto aos principais itens de manutenção abrangidos, estão a troca de lubrificantes, filtros, pneus e serviços de engraxar e lavar os veículos. A estimativa a respeito desses itens resultou em um montante de $R \$$ $2.043,00$ no primeiro e terceiros anos da vida útil prevista para o veículo e $R \$ 8.013,00$ no segundo e quarto anos de vida útil (aumento devido à troca de pneus que ocorre a cada 24 meses). 
Outro fator que representa uma parcela do CTP/TCO é o custo com a folha de pagamento dos motoristas que trafegam com os ônibus que transportam os funcionários da empresa. Com isso, a empresa tem que contratar dois motoristas, tendo em vista que as "linhas" de transporte ficam em sentidos opostos e porque se trata de um único turno de trabalho, o que faz com que os colaboradores sejam trazidos à fábrica e levados de volta aos seus bairros nos mesmos horários. Em decorrência disso, foi calculado o gasto relativo aos motoristas, conforme resumido na Tabela 5.

Tabela 5

Custo com folha de pagamento - Mercedes-Benz

\begin{tabular}{lcccc}
\hline \multicolumn{1}{c}{ Itens } & Ano 1 & Ano 2 & Ano 3 & Ano 4 \\
\hline a) Salários/Encargos $\mathrm{R} \$$ & $18.000,00$ & $18.000,00$ & $18.000,00$ & $18.000,00$ \\
b) Férias/Encargos $\mathrm{R} \$$ & $1.995,00$ & $1.995,00$ & $1.995,00$ & $1.995,00$ \\
c) $13^{\circ}$ Sal./Encargos $\mathrm{R} \$$ & $1.500,00$ & $1.500,00$ & $1.500,00$ & $1.500,00$ \\
$5=\mathrm{a}+\mathrm{b}+\mathrm{c})$ Custo total com folha de pagto. $\mathrm{R} \$$ & $21.495,00$ & $21.495,00$ & $21.495,00$ & $21.495,00$ \\
\hline
\end{tabular}

Nota. Fonte: elaborada pelos autores.

Dessa forma, calcularam-se os gastos com mão de obra de acordo com o salário e encargos estabelecidos legalmente, em que foi levado em conta o salário-base dos motoristas e os respectivos encargos, além dos gastos com férias/encargos e décimoterceiro salário/encargos. Com isso, foi apurado o montante anual de $R \$ 21.495,00$ referentes ao custo total anual com folha de pagamentos por motorista.

Em seguida, passou-se ao cálculo do custo referente ao consumo de combustíveis, nos moldes do exposto na Tabela 6. 
Tabela 6

Custo com combustível - Mercedes-Benz

\begin{tabular}{lcccc}
\hline \multicolumn{1}{c}{ Itens } & Ano 1 & Ano 2 & Ano 3 & Ano 4 \\
\hline a) Custo de compra do litro $\mathrm{R} \$$ & 3,29 & 3,29 & 3,29 & 3,29 \\
b) Consumo mensal estimado (litros) & 200 & 200 & 200 & 200 \\
c) Número de meses de uso/ano & 11 & 11 & 11 & 11 \\
6=aXbXc) Custo com combustível $\mathrm{R} \$$ & $7.238,00$ & $7.238,00$ & $7.238,00$ & $7.238,00$ \\
\hline
\end{tabular}

Nota. Fonte: elaborada pelos autores.

O gasto com combustível é um fator de extrema importância no cálculo do CTP/TCO, visto que são os valores mais significativos em comparação com os demais fatores abrangidos. Assim, na Tabela 6, estão especificados os valores previstos para os gastos com combustível durante a vida útil do veículo, levando-se em consideração o preço vigente do combustível e a quilometragem a ser percorrida durante o período em que o veículo seria efetivamente utilizado. Ou seja, desconsiderando-se os dias em que o veículo ficaria ocioso (como durante as férias coletivas da fábrica e os finais de semana, por exemplo).

Assumiu-se, então, que o valor (em $R \$$ ) do custo de compra do litro de combustível previsto para os meses da vida útil estimada seria o mesmo que vigia à época do estudo. O citado critério foi adotado por causa da volatilidade dos preços praticados no comércio de combustíveis para veículos atualmente no Brasil, o que dificulta estimativas a respeito.

Por outro ângulo, no caso de veículos, há um gasto periódico com as revisões feitas em intervalos específicos de tempo. No caso em tela, optou-se por estimar o provável dispêndio de recursos financeiros com as revisões de freios e molas, como consta da Tabela 7. 
Tabela 7

Custo com revisões periódicas - Mercedes-Benz

\begin{tabular}{|c|c|c|c|c|}
\hline Itens & Ano 1 & Ano 2 & Ano 3 & Ano 4 \\
\hline a) Freios ( $R \$ 390$ a cada 24 meses) $R \$$ & - & 390 & - & 390 \\
\hline b) Molas ( $R \$ 1.500$ a cada 12 meses) $R \$$ & $1.500,00$ & $1.500,00$ & $1.500,00$ & $1.500,00$ \\
\hline $7=a+b)$ Custo com revisões periódicas $R \$$ & $1.500,00$ & $1.890,00$ & $1.500,00$ & $1.890,00$ \\
\hline
\end{tabular}

Nota. Fonte: elaborada pelos autores.

No caso dos freios, estes costumam ser revisados a cada 24 meses, totalizando o valor de $\mathrm{R} \$ 390,00$ a cada dois anos, enquanto que a revisão de molas é feita anualmente e tem custo próximo de $\mathrm{R} \$ 1.500,00$ (conforme a estimativa do responsável pelo trabalho de manutenção dos veículos). Assim, o valor das manutenções varia conforme o ano e a necessidade de reparos: no âmbito dos anos 1 e 3, estimou-se que serão gastos $R \$ 1.500,00$ e, nos anos 2 e 4 , o custo passaria para algo em torno de $R \$$ 1.890,00, como mostrado na Tabela 7.

A etapa seguinte abordou o valor associado à depreciação dos veículos, uma vez que há de se fazer a partir desse cálculo uma espécie de "reserva de fundos" que possibilite, ao final da vida útil, a substituição dos bens. Nesse sentido, a Tabela 8 evidencia os valores considerados no cálculo efetuado a respeito do ônibus MercedesBenz.

Tabela 8

Custo com depreciação anual - Mercedes-Benz

\begin{tabular}{lcccc}
\hline \multicolumn{1}{c}{ Itens } & Ano 1 & Ano 2 & Ano 3 & Ano 4 \\
\hline a) Valor do veículo $\mathrm{R} \$$ & $20.646,71$ & $20.646,71$ & $20.646,71$ & $20.646,71$ \\
b) Vida útil estimada (em anos) & 5 & 5 & 5 & 5 \\
8=a/b) Custo com depreciação anual $\mathrm{R} \$$ & $4.129,34$ & $4.129,34$ & $4.129,34$ & $4.129,34$ \\
\hline
\end{tabular}

Nota. Fonte: elaborada pelos autores. 
Como estimativa de depreciação do ônibus Mercedes-Benz foi utilizado o critério que levou em conta o valor do veículo ( $\mathrm{R} \$ 20.646,71)$ dividido pelo número de anos de vida útil previsto para o mesmo (cinco anos, no caso). Calculou-se, então, uma depreciação de $20 \%$ ao ano, o que totalizou $R \$ 4.129,24$ por ano ao longo do período em que a empresa pretende utilizar o bem. Contudo, cabe ressaltar que foram utilizados cinco anos (mesmo que a vida útil prevista tenha sido de quatro anos) porque considerou-se a possível existência de um valor residual por ocasião do término do período de uso dos veículos. Assim, em virtude da dificuldade de estimar algum valor a respeito, utilizou-se o valor equivalente a um ano de depreciação como o possível valor residual.

\subsection{Síntese e Comparativo dos Valores Apurados como CTP/TCO}

Com os cálculos realizados e descritos de forma detalhada na seção precedente, foi reunido um conjunto de valores a respeito do CTP/TCO dos dois veículos abrangidos nesta pesquisa, sendo que, na Tabela 9, estão representados somente os dados referentes ao ônibus Mercedes-Benz, por restrição de espaço no texto. 
Custo Total de Propriedade de Veículos de Transporte de Funcionários: Estudo de Caso

Nelize Aparecida de Souza, Rodney Wernke, Antonio Zanin

Tabela 9

Resumo do custo total de propriedade - Ônibus Mercedes-Benz

\begin{tabular}{|c|c|c|c|c|c|c|}
\hline Itens & Ano 0 & Ano 1 & Ano 2 & Ano 3 & Ano 4 & Total \\
\hline 1) Custo de Aquisição $R \$$ & $20.646,71$ & - & - & - & - & $20.646,71$ \\
\hline $\begin{array}{l}\text { 2) Custo do capital aplicado } R \$ \\
\text { 3) Custo total da documentação }\end{array}$ & - & $1.393,65$ & $1.393,65$ & $1.393,65$ & $1.393,65$ & $5.574,61$ \\
\hline $\begin{array}{l}\mathrm{R} \$ \\
\text { 4) Custo total com manutenção }\end{array}$ & - & 646,71 & 646,71 & 646,71 & 646,71 & $2.586,84$ \\
\hline $\begin{array}{l}\mathrm{R} \$ \\
5 \text { ) Custo total com folha de }\end{array}$ & - & $2.043,00$ & $8.013,00$ & $2.043,00$ & $8.013,00$ & $20.112,00$ \\
\hline pagtos. $\mathrm{R} \$$ & - & $21.495,00$ & $21.495,00$ & $21.495,00$ & $21.495,00$ & $85.980,00$ \\
\hline $\begin{array}{l}\text { 6) Custo com combustível } R \$ \\
\text { 7) Custo com revisões }\end{array}$ & - & $7.238,00$ & $7.238,00$ & $7.238,00$ & $7.238,00$ & $28.952,00$ \\
\hline $\begin{array}{l}\text { periódicas } R \$ \\
\text { 8) Custo com depreciação anual }\end{array}$ & - & $1.500,00$ & $1.890,00$ & $1.500,00$ & $1.890,00$ & $6.780,00$ \\
\hline $\begin{array}{l}\mathrm{R} \$ \\
9=1+\ldots 8) \text { Custo Total de Propr. }\end{array}$ & - & $4.129,34$ & $4.129,34$ & $4.129,34$ & $4.129,34$ & $16.517,37$ \\
\hline $\begin{array}{l}\mathrm{R} \$ \\
10 \text { ) Valor residual (revenda do } \\
\text { veículo ao final da vida útil) } R \$ \\
11=9-10 \text { ) Valor Final do Custo }\end{array}$ & $20.646,71$ & $38.445,70$ & $44.805,70$ & $38.445,70$ & $44.805,70$ & $\begin{array}{r}187.149,53 \\
-4.129,34\end{array}$ \\
\hline $\begin{array}{l}\text { Total de Propriedade } R \$ \\
\text { 12) Quilometragem total } \\
\text { estimada durante a vida útil }\end{array}$ & & & & & & $183.020,19$ \\
\hline $\begin{array}{l}\text { prevista } \\
13=11 / 12 \text { ) Custo total de } \\
\text { propriedade por quilômetro }\end{array}$ & & & & & & 26.400 \\
\hline rodado $\mathrm{R} \$$ & & & & & & 6,93 \\
\hline
\end{tabular}

Nota. Fonte: elaborada pelos autores.

Com a mensuração de todos os custos decorrentes da aquisição e manutenção dos veículos durante as suas respectivas vidas úteis, foi possível apurar o Custo Total de Propriedade. No caso do ônibus Mercedes-Benz, os dados da Tabela 9 permitem dessumir que o CTP/TCO atingiu $\mathrm{R} \$ 187.149,53$ (item/linha 9 da tabela citada) e foi formado pelos fatores "Custo de Aquisição", "Custo do capital aplicado", "Custo total da documentação", "Custo total com manutenção", "Custo total com folha de pagamentos", "Custo com combustível", "Custo com revisões periódicas" e "Custo com depreciação anual". 
Deste valor, foram subtraídos $\mathrm{R} \$ 4.129,34$ a título de valor residual (item/linha 10), que poderia representar um encaixe de recursos pela venda do veículo ao término da vida útil deste, o que levou ao valor final do CTP/TCO de $R \$ 183.020,19$. Assumindo-se que a previsão de quilometragem total a ser percorrida pelo veículo seria de $26.400 \mathrm{~km}$ nos quatro anos previstos, o custo total de propriedade por quilômetro rodado ficou em $R \$ 6,93$ (conforme registrado na última linha da Tabela 9).

Como os referidos cálculos foram feitos também para o segundo veículo, cabe comparar o desempenho dos dois ônibus nos respectivos contextos, nos moldes do expresso de forma sintética na Tabela 10.

Tabela 10

Comparativo entre os dois veículos

\begin{tabular}{|c|c|c|c|c|}
\hline & $\begin{array}{l}\text { Ônibus M.- } \\
\text { Benz }\end{array}$ & & $\begin{array}{l}\text { Ônibus } \\
\text { Volkswagen }\end{array}$ & \\
\hline Itens & Valores & \% do CTP & Valores & \% do CTP \\
\hline $\begin{array}{l}\text { 1) Custo de Aquisição (veículo + } \\
\text { documentos) } R \$\end{array}$ & $20.646,71$ & $11,28 \%$ & $60.646,71$ & $20,91 \%$ \\
\hline 2) Custo do capital aplicado $R \$$ & $5.574,61$ & $3,05 \%$ & $20.468,26$ & $7,06 \%$ \\
\hline 3) Custo total da documentação $R \$$ & $2.586,84$ & $1,41 \%$ & $3.233,55$ & $1,11 \%$ \\
\hline 4) Custo total com manutenção $R \$$ & $20.112,00$ & $10,99 \%$ & $27.785,00$ & $9,58 \%$ \\
\hline 5) Custo total com folha de pagamentos $R \$$ & $85.980,00$ & $46,98 \%$ & $107.475,00$ & $37,05 \%$ \\
\hline 6) Custo com combustível $R \$$ & $28.952,00$ & $15,82 \%$ & $21.715,00$ & $7,49 \%$ \\
\hline 7) Custo com revisões periódicas $R \$$ & $6.780,00$ & $3,70 \%$ & $8.342,00$ & $2,88 \%$ \\
\hline $\begin{array}{l}\text { 8) Custo com depreciação anual } R \$ \\
9=1+\ldots 8 \text { ) Custo Total de Propriedade do }\end{array}$ & $16.517,37$ & $9,02 \%$ & $50.538,93$ & $17,42 \%$ \\
\hline $\begin{array}{l}\text { veículo } R \$ \\
10 \text { ) Valor residual (revenda do veículo ao }\end{array}$ & $187.149,53$ & $102,26 \%$ & $300.204,45$ & $103,48 \%$ \\
\hline $\begin{array}{l}\text { final da vida útil) } R \$ \\
11=9-10 \text { ) Valor Final do Custo Total de }\end{array}$ & $-4.129,34$ & $-2,26 \%$ & $-10.107,79$ & $-3,48 \%$ \\
\hline $\begin{array}{l}\text { Propriedade } R \$ \\
\text { 12) Quilometragem total prevista para a vida }\end{array}$ & $183.020,19$ & $100,00 \%$ & $290.096,66$ & $100,00 \%$ \\
\hline $\begin{array}{l}\text { útil }-\mathrm{Km} \\
13=11 / 12 \text { ) Custo total de propriedade por } \mathrm{km}\end{array}$ & 26.400 & - & 39.600 & - \\
\hline rodado $R \$$ & 6,933 & - & 7,326 & - \\
\hline
\end{tabular}

Nota. Fonte: elaborada pelos autores. 
Constatou-se, então, que o custo de aquisição do veículo Mercedes-Benz representou somente $11,28 \%$ do CTP/TCO, enquanto que este fator equivaleu a $20,91 \%$ no caso do ônibus Volkswagen. Com isso, os demais fatores considerados no cálculo participaram com $88,72 \%$ no contexto do primeiro e $79,09 \%$ na realidade prevista para o segundo.

Pelo prisma dos valores monetários, o ônibus Mercedes-Benz totalizou o valor de $\mathrm{R} \$ 183.020,19$ para uma quilometragem total estimada de $26.400 \mathrm{~km}$, o que implicou custo de $R \$ 6,933$ por quilômetro rodado com este veículo. No que tange ao ônibus Volkswagen, o valor total apurado chegou a $R \$ 290.096,66$ para uma quilometragem prevista de $39.600 \mathrm{~km}$, acarretando custo de $\mathrm{R} \$ 7,326$ por quilômetro a ser percorrido. Destarte, o custo por quilômetro ficou mais caro em aproximadamente $R \$ 0,393$ no caso do ônibus Volkswagen em relação ao Mercedes-Benz, o que representaria um gasto adicional em torno de $R \$ 15.566,38$ (39.600 $\mathrm{km} \times \mathrm{R} \$ 0,393 / \mathrm{km})$ ao longo dos 60 meses de uso previstos para este ônibus.

Outra aplicação desses resultados é no sentido de subsidiar a decisão sobre a viabilidade de manter a frota própria ou terceirizar esta atividade de transporte. Para essa finalidade, bastaria comparar o preço por quilômetro rodado dos veículos, conforme acima, com o valor que seria cobrado por uma empresa terceirizada para efetuar o mesmo tipo de serviço. Se o prestador de serviços tiver custo por quilômetro menor, com a mesma qualidade de transporte, economicamente seria mais interessante terceirizar o serviço.

Como não foram encontradas pesquisas anteriores sobre a utilização do conceito do CTP/TCO em frota de ônibus para transporte de funcionários, a comparação a respeito fica prejudicada. Entretanto, os resultados acima apontam a relevância de identificar os custos da parte "submersa" do iceberg, segundo a figura de linguagem utilizada por Bierma e Waterstraat (2004).

Nesse rumo, os resultados citados mostraram que os fatores transacionais e pós-transacionais (que totalizaram $88,72 \%$ e $79,09 \%$ do CTP/TCO, respectivamente para os veículos Mercedes-Benz e Volkswagen) são mais expressivos que o custo de 
compra dos dois ônibus. Esse cenário se assemelha ao identificado por Camargo et al. (2016), que mensuraram duas marcas de caminhão "raçãozeiro" e apuraram que os elementos transacionais e pós-transacionais representaram entre $79,79 \%$ e $81,45 \%$ do custo total previsto.

\section{CONSIDERAÇÕES FINAIS}

A pesquisa objetivou identificar os custos associados à propriedade de dois veículos utilizados para transportar funcionários de uma determinada indústria de confecções. Nesse sentido, os cálculos expostos nas seções precedentes permitem concluir que tal objetivo foi atingido e proporcionaram os resultados resumidos na sequência.

Mesmo que o custo mais comumente utilizado para decidir sobre aquisição de bens seja o valor a ser despendido na compra, o raciocínio com base no CTP/TCO possibilita ampliar o leque de fatores. Nessa direção, no caso em lume, foram considerados também o "custo do capital aplicado", o "custo total da documentação", o "custo total com manutenção", o "custo total com folha de pagamentos", o "custo com combustível", o "custo com revisões periódicas", o "custo com depreciação anual" e o possível "valor residual" ao término da vida útil dos veículos. A partir desse procedimento, constatou-se que esses outros fatores (exceto o custo de aquisição) representaram a parte mais substancial do CTP/TCO: $88,72 \%$ no veículo MercedesBenz e 79,09\% no caso do ônibus da Volkswagen.

Além disso, quanto aos montantes finais calculados, chegou-se a valores distintos para os dois ônibus, sendo que o veículo Mercedes-Benz teve desempenho superior em relação ao Volkswagen, especialmente se considerado o parâmetro de custo (em $\mathrm{R} \$$ ) por quilômetro rodado: $\mathrm{R} \$ 6,933$ contra $\mathrm{R} \$ 7,326$. A diferença verificada de $\mathrm{R} \$ 0,393$ a cada 1.000 metros percorridos equivale a aproximadamente $5,67 \%$ a favor do primeiro ônibus $(R \$ 0,393 / R \$ 6,933$ * 100$)$. 
Destarte, como possíveis contribuições deste estudo é pertinente destacar dois pontos. O primeiro é no sentido de contribuir, de forma prática, com a administração da entidade em termos de proporcionar uma avaliação mais acurada acerca do desempenho dos dois veículos na realidade operacional cotidiana. Com isso, destacouse que, mantidas as condições simuladas ou previstas, um dos veículos é economicamente mais viável que o outro, além de subsidiar decisões sobre terceirizar ou manter frota própria deste tipo de veículo.

No âmbito teórico, considera-se que esta pesquisa contribuiu com a evidenciação de uma aplicação do conceito de CTP/TCO num contexto ainda não identificado em pesquisas correlatas (frota de veículos para transporte de funcionários). Com isso, além de atestar a viabilidade de utilizar essa concepção, expandiu-se um pouco mais o campo de utilização do custo total de propriedade, o que pode facilitar para que outras empresas empreguem a mesma metodologia para realizar avaliações semelhantes.

Quanto às limitações do estudo, por ser um estudo de caso, as conclusões oriundas estão circunscritas ao contexto da empresa pesquisada. Assim, não cabe extrapolar os resultados para outras realidades empresariais, mesmo que assemelhadas. Outra restrição a considerar está vinculada ao fato de que, para determinados fatores, foram utilizadas estimativas que podem ou não ser confirmadas posteriormente. Mas, como toda projeção de valores para um período futuro carrega algum nível de subjetividade, os valores ora considerados tendem a ser aceitáveis dentro das condições identificadas no âmbito da empresa objeto da pesquisa.

Como sugestões para trabalhos futuros, recomenda-se uma aplicação semelhante em outra(s) empresa(s) com o objetivo de comparar os resultados. Além disso, seria interessante aprimorar o referido cálculo utilizando o conceito de valor presente para trazer os valores monetários considerados para um mesmo poder aquisitivo de moeda. 


\section{REFERÊNCIAS}

Ahrens, T., \& Chapman, C. S. (2007). Management accounting as practice. Accounting, Organizations and Society, 37(1-2), p.1-27.

Andrade, M. M. (2002). Como preparar trabalhos para cursos de pós-graduação: noções práticas. (5a ed.). São Paulo: Atlas.

Antunes, M. T. P., Mendonça Neto, O. R. de, \& Vieira, A. M. (2016). Pesquisa intervencionista: uma alternativa metodológica para os mestrados profissionais em Contabilidade e Controladoria. Atas - Investigação Qualitativa em Educação, CIAIQ2016, v. $1, \quad 2016 . \quad$ Recuperado de: $<$ http://proceedings.ciaiq.org/index.php/ciaiq2016/article/view/ 667>. Acesso em: 06/jul/2018.

Baldvinsdottir, G., Mitchell, F., \& Norreklit, H. (2010). Issues in the relationship between theory and practice in management accounting. Management Accounting Research, 21(2), p. 79-82.

Barichello, R., Carvalho, C. C., Pereira, G. L., Luza, L., \& Deimling, M. F. (2014). Custo Total de Propriedade (TCO) na aquisição de pneus em uma empresa de terraplanagens e pavimentação. In: CONBREPRO. Congresso Brasileiro de Engenharia de Produção, Ponta Grossa, PR, Brasil, 4.

Bartunek, J. M., \& Rynes, S. L. (2014). Academics and practitioners are alike and unlike: the paradoxes of academic-practitioner relationships. Journal of Management, 40(5), p.1181-1201.

Bierma, T. J., \& Waterstraat, F. L. (2004). Total cost of ownership for metalworking fluids. WMRC reports. Waste Management and Research Center, Apr, 2004. Recuperado de: <http://www.istc.illinois.edu/main_sections/info_services/library_docs/RR/RR105.pdf >. Acesso em: 18/set/2018.

Camargo, T. F., Zanin, A., Wernke, R., \& Scheren, G. (2016). Custo Total de Propriedade: estudo de caso em caminhão (raçãozeiro) utilizado na cadeia de suprimentos da suinocultura. In: Congresso de Contabilidade da UFRGS, 1., 2016, Porto Alegre/RS. I Congresso de Contabilidade da UFRGS, Porto Alegre/RS.

Carr, L. P., \& Ittner, C. D. (1992). Measuring the cost of ownership. Journal of Cost Management, 6(3), p. 42-49. 
Cherobim, A. P. M. S., \& Espejo, M. M. dos S. B. (2011). Finanças pessoais: conhecer para enriquecer. São Paulo: Atlas.

Coleman, L. (2014). Why finance theory fails to survive contact with the real world: a fund manager perspective. Critical Perspectives on Accounting, 25(3), p.226-236.

Coser, T., \& Souza, M. A. (2017). Custo Total de Uso e Propriedade (TCO): estudo de caso em uma indústria gráfica do Rio Grande do Sul (RS). Contabilidade Vista \& Revista, 28(1), p.67-88.

Degraeve, Z., \& Roodhooft, F. (1999). Improving the efficiency of the purchasing process using total cost of ownership information: the case of heating electrodes at Cockerill Sambre S.A. European Journal of Operational Research, 112(1), p.42-53.

Deimling, M. F., Giongo, J., \& Zanrosso, D. F. (2012). Custo Total de Propriedade: adoção no setor de compras da Usina Foz de Chapecó. Revista ABCustos, 7(3), p.1-58.

Departamento Estadual de Trânsito de Santa Catarina [DETRAN-SC]. Licenciamento anual. Recuperado de: $<$ http://www.detran.sc.gov.br/index.php/veiculos/licenciamento-anual/120-veiculoslicenciamento-anual/356-veiculos-licenciamento-anual-6>. Acesso em: 20/ago/ 2018.

Eisenbach Neto, F. J., Magalhães, V. C. D., \& Santos, D. F. (2013). Análise dos custos logísticos utilizando a metodologia custo total de propriedade (TCO - Total Cost of Ownership) como estratégia no processo de compras do setor de construção civil. Administração de Empresas em Revista, 12(13), p. 27-39.

Ellram, L. M., \& Siferd, S. P. (1993). Purchasing: the cornerstone of total cost of ownership concept. International Journal of Business Logistics, 14(1), p. 163-184.

Ellram, L. M. (1995). Total cost of ownership: an analysis approach for purchasing. International Journal of Physical Distribution \& Logistics Management. Arizona, 28(8), p.4-25.

Faria, A. C. de. (2003). Custos logísticos: uma abordagem na adequação das informações de Controladoria à gestão da logística empresarial. (Tese de Doutorado em Contabilidade). Faculdade de Economia, Administração, Contabilidade e Atuária - FEA/USP, São Paulo, SP, Brasil. 
Gasparetto, V., Freires, F. G., Bornia, A. C., \& Rodrigues, C. T. (1999). Custeio da cadeia logística: uma análise das ferramentas disponíveis. In: Congresso Brasileiro de Custos. São Paulo, SP, Brasil, 6.

Gasparetto, V., \& Silva, I. S. T. (2004). Custo Total de Propriedade (TCO): uma ferramenta auxiliar na gestão de custos. In: Congresso Brasileiro de Custos, Porto Seguro, Bahia. Brasil, 11.

Gil, A. C. (1999). Métodos e técnicas de pesquisa social. São Paulo: Atlas.

Grant, D. B. (2013). Gestão de logística e cadeia de suprimentos. São Paulo: Saraiva.

Ignacio, A. A. V., Fernandes, E., Sampaio, L. M. D., \& Araújo, R. S. B. (2016). O papel do custo total de propriedade (TCO) no gerenciamento da cadeia de suprimentos. In: Simpósio de Engenharia de Produção - SIMPEP, Bauru, SP, Brasil, 13.

Lukka, K. (2010). The roles and effects of paradigms in accounting research. Management Accounting Research, 21(2), p.110-115.

Malmi, T., \& Granlund, M. (2009). In search of management accounting theory. European Accounting Review, 8(3), p.597-620.

Marques, K. C. M., Camacho, R. R., \& Alcantara, C. C. V. de. (2015). Avaliação do rigor metodológico de estudos de caso em contabilidade gerencial publicados em periódicos no Brasil. Revista Contabilidade \& Finanças. USP. São Paulo, 26(67), p.27-42.

Martins, E. (2010). Contabilidade de custos. (10a ed.). São Paulo: Atlas.

Martins, P. G., \& Alt, P. R. C. (2006). Administração de materiais e recursos patrimoniais. (2a ed.). São Paulo: Saraiva.

Mochnacz, J. C., Deimling, M. F., Barichello, R., Kliemann Neto, J. F., \& Casarotto Filho, N. (2017). Aplicação do Custo Total de Propriedade (CTP) em uma agroindústria de grande porte.Custos e @gronegócio OnLine,13(3), p.312-339.

Muller, C. J., \& Panitz, C. O. V. (2001). O uso da ferramenta de Total Cost of Ownership (TCO) como técnica para avaliação e seleção de fornecedores. In: Congresso Brasileiro de Custos, São Leopoldo, RS, Brasil, 8.

Parisi, C., \& Megliorini, E. (2011). Contabilidade gerencial. São Paulo: Atlas. 
Porter, M. (2011). Quando os CEOS entrevistam Porter. Revista HSM Management, n. 84, jan./fev.

Richardson, R. J. (1999). Pesquisa social: métodos e técnicas. São Paulo: Atlas.

Scapens, R. W. (2006). Understanding management accounting practices: a personal journey. The British Accounting Review, 38(1), p.1-30.

Schmidt, P., Santos, J. L. dos, Pinheiro, P. R., \& Nunes, M. M. da S. (2013). A importância do Total Cost of Ownership no gerenciamento da cadeia de suprimentos. Revista Contexto, 3(25), p.20-31.

Seal, W. (2010). Managerial discourse and the link between theory and practice: from $\mathrm{ROI}$ to value based management. Management Accounting Research, 21(2), p.95109.

Wernke, R. (2014). Custos logísticos: ênfase na gestão financeira de distribuidoras de mercadorias e de transportadoras rodoviárias de cargas. Maringá: Editora Mag.

Wernke, R. (2015). Custo total de propriedade de automóveis de uso particular: aplicação comparativa em dois modelos populares (1.0). Revista Brasileira de Contabilidade, 211, p.30-45.

Wernke, R., Lembeck, M., \& Mendes, E. Z. (2012). Terceirizar ou "desterceirizar" o transporte: estudo de caso. Revista Mundo Logística, 5(27), p.28-36.

Yin, R. K. (2001). Estudo de caso: planejamento e métodos. (2a ed.). Porto Alegre: Bookmam.

Data de Submissão: 03/10/2018

Data de Aceite: 18/02/2019 